\title{
ANALISA PENGARUH COST LEADERSHIP, DIFFERENTATION STRATEGY DAN MARKET ORIENTATION TERHADAP KINERJA PERUSAHAAN
}

\author{
Lily Purwianti \\ ${ }^{1)}$ Program Studi Manajemen, Universitas Internasional Batam \\ Jl Gajah Mada, Baloi Sei Ladi Batam 29442 \\ email: lpurwianti@yahoo.com
}

\begin{abstract}
The main purposes of this study is to analyze the relationship of cost leadership, differentiation strategy, market orientation and organization performance. The research sample are souvenirs shop in Batam City. Multiple regression analysis to test the hypothesis. The results of this study are information about cost leadership, differentiation strategies, market orientation towards company performance. The results showed that cost leadership, differentiation strategy, market orientation has significant efect on organization performance.
\end{abstract}

Keywords : Cost leadership, Differentation Strategy, Market Orientation, Organization Performance

\begin{abstract}
Abstrak
Penelitian ini mempunyai tujuan untuk menganalisis pengaruh variabel cost leadership, differentiation strategy, market orientation terhadap Kinerja Perusahaan. Sampel penelitian ini adalah toko oleh oleh atau cendramata di Kota Batam. Analisa Regresi berganda dilakukan untuk menguji hipotesis. Hasil penelitian ini adalah terdapat pengaruh antara cost leadership, differentiation strategy, market orientation terhadap kinerja perusahaan.
\end{abstract}

Kata kunci : Biaya Kepemimpinan, Strategi Diferensiasi, Orientasi Pemasaran, Kinerja Perusahaan

\section{PENDAHULUAN}

Sektor pariwisata merupakan salah satu sektor ekonomi terbesar di dunia, sektor ini mampu menciptakan lapangan kerja, mendorong ekspor, dan menghasilkan kemakmuran di seluruh dunia. Sektor ini menyumbang $10,4 \%$ dari PDB global dan 313 juta pekerjaan, atau 9,9\% dari total pekerjaan, pada tahun 2017. (World Travel and Tourism Council
\& Oxford Economics, 2018) Dengan ditetapkannya pariwisata sebagai leading sector di Indonesia maka Indonesia menduduki peringkat 9 dalam pariwisata dunia. Sektor pariwisata juga memberikan kontribusi bagi perekonomian Indonesia. Hal ini bisa dilihat dengan kenaikan devisa dari sektor pariwisata.dari tahun 2015-2017.(Kementerian Pariwisata Indonesia, 2017).

Tabel 1

Penerimaan Devisa sektor Pariwisata tahun 2015-2017

Tahun Devisa (Triliun Rp )

\begin{tabular}{ll}
\hline $\mathbf{2 0 1 5}$ & 175,71 \\
$\mathbf{2 0 1 6}$ & 176,23
\end{tabular}

2017

202,13 
Kepulauan Riau menduduki posisi ke 3 dari banyaknya wisatawan yang masuk ke Indonesia.(BPS, 2019). Wisatawan yang datang ke Kepulauan Riau selain Dengan itu diperlukanya strategi untuk dapat bertahan salah satunya adalah

Saat ini lingkungan kompetitif dan ekonomi terus berubah, yang sepenuhnya mengalihkan perhatian perusahaan dan memaksanya untuk berusaha keras bagaimana mempertahankan sumber daya fisik dan tidak berwujud untuk meningkatkan kinerja mereka dan membangun keunggulan kompetitif (Mata \& Aliyu, 2014). Cost Leadership adalah alat organisasi utama yang digunakan dalam meningkatkan kinerja industri dan mempromosikan keunggulan kompetitif (Azim, Abdullah, \& Gorondutse, 2017). Oleh karena itu, cost leadership merupakan faktor yang berpengaruh yang dapat mengarah pada kinerja perusahaan yang aktif. Demikian pula, market orientation telah diidentifikasi sebagai katalis untuk meningkatkan kinerja bisnis yang efektif dengan mempertimbangkan kebutuhan pelanggan sebagai filosofi organisasi teratas (Hassan et al., 2018). Oleh karena itu, penting untuk mengusulkan bahwa Cost Leadership dan market orientation memiliki pengaruh dalam menciptakan keuntungan kompetitif dan meningkatkan kinerja organisasi (Waddel \& Stewart, 2008). Karena salah satu unsur penting kesuksesan di pasar adalah keunggulan kompetitif ((Birjandi, Jahromi, Darabi, \& Birjandi, 2014). Agar organisasi dapat berfungsi secara aktif, organisasi harus terbiasa dengan medan operasinya. Oleh karena itu, semua komponen kinerja perusahaan harus diharapkan, dikendalikan, dievaluasi, dan dikonsolidasikan dalam pengambilan keputusan tingkat atas.

Selain cost leadership dan market orientation dalam mempengaruhi kinerja, differentiation strategy juga dapat membutuhkan akomodasi, dibutuhkan juga oleh oleh atau cendramata dari tempat wisata yang dituju. Di kota Batam terdapat banyak toko oleh oleh atau cendramata. dengan mempunyai kinerja yang baik (Hassan et al., 2018)

mempengaruhi kinerja organisasi (Abu Aliqah, 2012). Menurut teori Porter untuk membangun keunggulan kompetitif biasanya melalui cost leadership dan differentiation strategy, biasanya perusahaan memilih hanya satu dari dua ini (Kharub, Patle, \& Sharma, 2016). Akan tetapi penelitian ini meggunakan kedua pendekatan dari teori Porter yaitu cost leadership dan differentiation strategy untuk meningkatan kinerja perusahaan., Mengingat pandangan berbasis sumber daya perusahaan (RBV), cost leadership , differentiation strategy dan market orientation dapat dipandang sebagai kemampuan strategis penting dan sumber daya organisasi yang berkorelasi bersama, dan diharapkan bahwa interaksi kedua strategi manajemen yang berbeda ini akan meningkatkan efisiensi dan kinerja perusahaan.

\section{Cost Leadership dan Kinerja Organisasi}

Kinerja perusahaan baik atau buruk sangat terkait dengan pemahaman yang jelas tentang faktor lingkungan dan pilihan strategi kompetitif (Ehie \& Muogboh, 2016). Porter menyebutkan bahwa perusahaan yang menekankan pada cost leadership menciptakan fasilitas skala efisien, menekankan pengurangan pengeluaran dan meminimalkan R\&D, tenaga penjualan, biaya iklan dan overhead. Dengan cost leadership, perusahaan dapat memperoleh keunggulan kompetitif atas pesaingnya hanya dengan memiliki pengembalian aset yang lebih tinggi dan dengan memproduksi produk dengan kualitas yang wajar (Kharub, Mor, \& Sharma, 2018). Cost leadership memiliki hubungan yang signifikan 
dengan kinerja perusahaan. Ini memungkinkan mereka untuk mencapai dan mempertahankan tujuan yang diinginkan untuk periode yang cukup lama. Di bawah sebagian besar kondisi, sebuah perusahaan yang mencapai tingkat kualitas produk yang signifikan meraih proporsi tinggi pangsa pasar dan menikmati manfaat dari peningkatan pertumbuhan penjualan. Selain itu, total unit biaya manufaktur dan distribusi bagian cenderung menurun dengan lebih banyak atau kurang tingkat seragam dengan setiap peningkatan persentase dalam output kumulatif perusahaan.

Strategi kepemimpinan biaya mendapat perhatian ilmiah yang lebih luas dalam banyak literatur manajemen dan pemasaran. Demikian pula, (GonzalezBenito \& Suarez-Gonzalez, 2010) menyelidiki seratus empat puluh delapan pabrikan Spanyol dan melaporkan bahwa keselarasan antara strategi bisnis ( dalam hal ini cost leadership ), tujuan manufaktur serta kemampuan manufaktur memengaruhi kinerja bisnis secara positif. Studi (Acquaah, 2011) meneliti pengaruh strategi bisnis pada kinerja bisnis keluarga. Sampel dari lima puluh empat bisnis keluarga digunakan. Hasil dari penelitian ini menunjukkan bahwa strategi bisnis kepemimpinan biaya dan diferensiasi menghasilkan keunggulan kompetitif untuk bisnis keluarga. Dalam nada yang sama, (Valipour, Birjandi, \& Honarbakhsh, 2012) mengemukakan tentang pengaruh strategi kepemimpinan biaya dan strategi diferensiasi produk pada kinerja perusahaan. Data dikumpulkan dari empat puluh lima perusahaan di Tehran Security Exchange (TSE), analisis regresi berganda digunakan untuk Cost Leadership dan kinerja perusahaan.

Atikiya, Mukulu, \& Waiganjo, 2015) mempelajari pengaruh cost leadership terhadap kinerja perusahaan manufaktur di Kenya. Dengan menggunakan data dari 131 perusahaan yang diambil dari 12 subsektor industri utama yang berlokasi di Nairobi dan sekitarnya, studi ini menetapkan bahwa temuan tersebut mengungkapkan bahwa kinerja perusahaan manufaktur secara signifikan dipengaruhi oleh cost leadership. (Birjandi et al., 2014) menyelidiki efek cost leadership pada ROA dan kinerja masa depan Perusahaan yang terdaftar di Bursa Efek Teheran. Menggunakan data dari 45 perusahaan di Tehran Security Exchange (TSE) selama 2009-2013, penelitian ini menetapkan bahwa di perusahaan-perusahaan dengan cost leadership ada hubungan positif antara rasio penjualan terhadap belanja modal dengan persentase pertumbuhan dalam penjualan. Temuan serupa ditemukan (Valipour et al., 2012) yang menemukan bahwa di perusahaan dengan strategi kepemimpinan biaya, ada hubungan positif antara leverage; strategi kepemimpinan biaya dan pembayaran dividen dengan kinerja.

Penelitian (Kharub et al., 2018) yang dilakukan pada perusahaan MSMEs yang berbeda sektor yaitu mechanical, automobile, electrical, electronics dan textile menghasilkan bahwa cost leadership berpengaruh terhadap kinerja organisasi. (Hassan et al., 2018) melakukan penelitian pada perusahaan manufaktur di Kano, Nigeria. Penelitian ini membuktikan bahwa cost leadership berpengaruh terhadap kinerja perusahaan. Penelitian ini serupa dengan penelitian (Atikiya et al., 2015; Hilman \& Kaliappen, 2014a; Hunjra, Faisal, \& Gulshion, 2017; Lo, 2012).

Berdasarkan argumen ini, hipotesis berikut dirumuskan:

$\mathrm{H} 1=$ Cost leadership strategy berpengaruh signifikan terhadap kinerja organisasi.

Differentiation strategy dan Kinerja Perusahaan

Strategi diferensiasi adalah serangkaian tindakan terpadu yang dilakukan untuk menghasilkan barang atau jasa (dengan biaya yang dapat diterima) yang menurut pelanggan berbeda dalam 
cara-cara yang penting bagi perusahaan. Peneliti sebelumnya telah menyempurnakan dan mengonseptualisasikan strategi diferensiasi di beberapa dimensi, termasuk diferensiasi produk, diferensiasi pemasaran, diferensiasi kualitas, diferensiasi layanan, dan strategi diferensiasi inovasi. Suatu perusahaan mungkin gagal di tengah dalam memilih strategi generik yang paling tepat. Untuk menghindari ketidakkonsistenan strategi generik seperti itu, sebuah perusahaan dapat mempertimbangkan untuk menggabungkan, hibrid, atau menggabungkan strategi generik ini berdasarkan sumber daya, kemampuan, dan pilihan strategis perusahaan (Espinorodríguez \& Chun, 2014). Jumlah penelitian telah menyelidiki efek dari strategi sumber pada kinerja organisasi dan menekankan pada membuat atau membeli sumber diffensiasi (Hilman \& Mohamed, 2011).

Tujuan dari mengejar strategi diferensiasi adalah untuk menawarkan produk atau layanan yang unik kepada pelanggan sehingga mendapatkan harga premium. Ini memfasilitasi ereksi perusahaan dari hambatan masuk dan mengurangi daya tawar pembeli melalui loyalitas pelanggan dan inelastisitas harga (Porter, 1980). Dengan kata lain, dengan menerapkan layanan khusus yang berbeda atau produk yang dipersonalisasi, perusahaan dapat membangun loyalitas pelanggan ketika produk atau layanan pengganti tidak tersedia di pasar. Karakteristik dari produk dan layanan dalam industri ini memungkinkan perusahaan untuk membebani pelanggan mereka dengan harga yang lebih tinggi daripada pesaing mereka berdasarkan biaya sistem pengiriman, kualitas layanan, dan saluran distribusi yang terlibat dalam menciptakan atau memproduksi produk dan layanan unik mereka. Miller dalam (Lo, 2012)lebih lanjut mengkategorikan strategi diferensiasi menjadi diferensiasi inovasi-produk dan diferensiasi pasar. Dia juga menjelaskan bahwa, dalam strategi diferensiasi inovasi-produk, sebuah perusahaan bertujuan untuk mengungguli para pesaingnya dengan menekankan produksi produk-produk yang kreatif, mutakhir, dan menarik, serta kualitas layanan, efisiensi, pengembangan produk baru, desain inovasi, dan mode atau gaya.

Strategi diferensiasi mencakup semua dalam ekonomi pasar dan merupakan cara yang berlaku untuk mendapatkan keunggulan kompetitif (Hingley, Sodano, \& Lindgreen, 2008; Pehrsson, 2016) . Literatur dalam manajemen strategis memberikan beberapa klasifikasi strategi bisnis yang menjelaskan bagaimana perusahaan bersaing dalam lingkungan pasar yang relevan (Cavusgil, Ghauri, \& Akcal, 2013)(Pehrsson, 2016)(Yuliansah, Rammal, \& Rose, 2016). Strategi diferensiasi Porter memberi peluang bisnis untuk menyatakan harga terbaik selain mempertahankan pangsa pasar yang lebih baik atau menjadi pemimpin pasar. Strategi diferensiasi sebagai bagian dari strategi tingkat bisnis dijalankan secara akal ketika bisnis memberikan signifikansi eksklusif atau lebih baik kepada pembeli dengan arah kualitas produk, fitur, atau dukungan tindak. Oleh karena itu, bisnis yang mengadopsi strategi diferensiasi dapat menyatakan biaya barang atau jasa lebih tinggi berdasarkan fitur, sistem alokasi, kualitas layanan, atau saluran pengiriman.(Nandakumar, K., Ghobadian, \& Regan, 2011; Teeratansirikool, Siengthai, Badir, \& Charoenngam, 2013)

Hubungan antara strategi dan kinerja telah diperiksa dalam berbagai karya, baik secara teoritis maupun empiris (Pehrsson, 2016; Teeratansirikool et al., 2013). Dalam studi empiris, hubungan antara strategi dan kinerja biasanya dioperasionalkan dengan menggunakan berbagai tindakan dan ide-ide eksplisit kausalitas yang didorong oleh kemajuan dalam penelitian strategi Ada sejumlah penelitian yang menetapkan bahwa bisnis yang memilih diferensiasi sebagai strategi 
kompetitif menghasilkan kinerja yang lebih baik daripada saingan(Teeratansirikool et al., 2013). Literatur sebelumnya memiliki strategi diferensiasi yang rumit sebagai salah satu strategi yang sesuai dalam strategi kompetitif untuk bisnis untuk meningkatkan kinerjanya ((Al-siwidi \& Al-Hosam, 2012)(Birjandi et al., 2014)(Hilman, Hai Kaliappen, 2014).

Berdasarkan paparan diatas maka hipotesis penelitian

H2 = Differentiation strategy berpengaruh signifikan terhadap Kinerja Perusahaan

\section{Market Orientation dan Kinerja Organisasi}

Hubungan Market Orientation dan

kinerja tampaknya menghasilkan temuan yang beragam, sehingga hubungan antara dan kinerja perusahaan tidak dapat disimpulkan. Frith dalam (Hassan et al., 2018) sebuah penelitian berpendapat tentang orientasi pasar untuk hubungan kinerja pada perusahaan minoritas dan milik wanita di Central Texas. Sampel seribu empat perusahaan kecil digunakan, dan temuan menunjukkan hasil yang beragam. Orientasi pasar ke hubungan kinerja adalah positif yang diukur dengan tingkat pertumbuhan penjualan dan retensi pelanggan, sementara itu, korelasi negatif ditemukan antara orientasi pasar terhadap kinerja yang diukur dengan pengembalian penjualan. Namun,(Mokhtar, 2009) meneliti seratus lima puluh delapan perusahaan manufaktur Malaysia, melalui survei kuesioner. Temuan menunjukkan bahwa tindakan dan perencanaan pasar berhubungan positif dengan kinerja keuangan.

Dalam nada yang sama, (Barnabas \& Mekoth, 2010) menilai apakah otonomi superior pada tingkat organisasi menghasilkan market orientation i dan kinerja pasar yang sangat baik. Sampel tiga ratus lima manajer cabang digunakan, menggunakan analisis regresi berganda untuk analisis data. Hasil nya di peroleh bahwa market orientation memiliki pengaruh yang significant terhadap kinerja perusahaan. (Shehu \& Mahmood, 2014) meneliti orientasi pasar untuk hubungan kinerja antara UKM Nigeria, dengan enam ratus empat puluh pemilik / manajer sebagai responden. Hasil analisis korelasi membentuk hubungan positif antara konstruk, sedangkan, hubungan negatif dilaporkan melalui hasil regresi berganda. Selain itu, (Ghanavati, 2014)) berpendapat tentang budaya perusahaan dan orientasi pasar dari kinerja UKM industri Iran, dengan sampel tiga ratus sembilan puluh dua manajer pemasaran eksekutif. Metode stratified sampling digunakan, dan pemodelan persamaan struktural digunakan untuk analisis data. Temuan ini menunjukkan efek tidak langsung positif dari budaya organisasi pada hubungan antara market orientation dan kinerja. Market Orientation memiliki fokus pada pelanggan dan pesaing, sehingga dapat meningkatkan kinerja bisnis (Fawzy, Abuzid, \& Abbas, 2017; Kocak, Carsrud, \& Oflazoglu, 2017; Oluwatoyin, Olufunke, \& Salome, 2018; Wilson, Perepelkin, Zhang, \& Vachon, 2014)

Berdasarkan argumen ini, hipotesis berikut dirumuskan:

$\mathrm{H} 3$ = Market orientation berpengaruh significant terhadap kinerja perusahaan.

\section{METODE PENELITIAN}

Populasi penelitian ini industri oleh oleh atau cendramata yang di Kepulauan Riau. Sampel penelitian ini adalah perusahahaan oleh oleh atau cendramata yang ada di Kota Batam. Unit analisisnya adalah perusahaan oleh oleh atau cendramata di Kota Batam. Metode sampel menggunkan purposive sampling. Responden penelitian ini adalah pemilik, manajer dari toko oleh oleh atau cendramata khas Batam.

Pengukuran Variabel yang digunakan dalam penelitian ini adalah Cost lesdership (5 item )yang diadopsi dari (Hunjra et al., 2017), Differentation Strategy (6 item) pyang diadopsi dari (Gorondutse \& Hilman, 2017), Market Orientation (10 item) yang diadopsi dari (Hilman \& 
Kaliappen, 2014b), Kinerja perusahaan (5 item) dari (Gorondutse \& Hilman, 2017). Semua variabel menggunkaan skala liker 5 point.

Gambar 1

Model penelitian

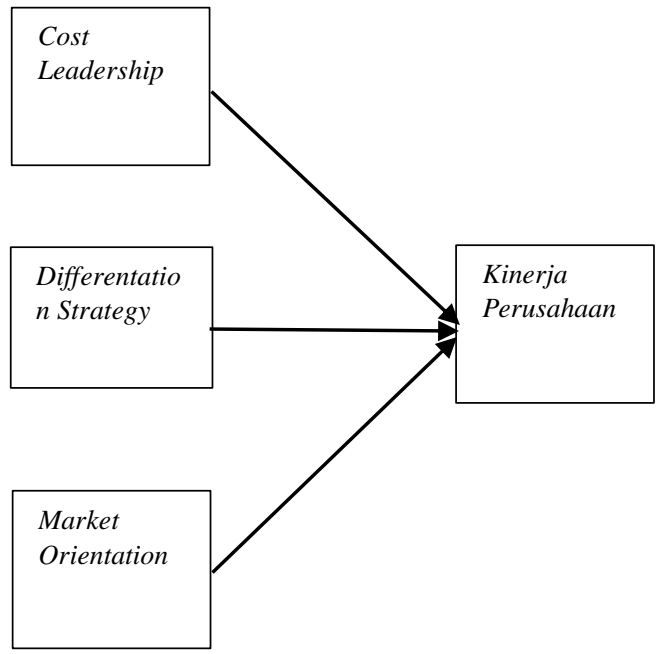

Hipotesis Penelitian

$\mathrm{H} 1=$ Cost Leadership berpengaruh signifikan terhadap Kinerja Perusahaan $\mathrm{H} 2$ = Differentation Strategy berpengaruh signifikan terhadap Kinerja Perusahaan $\mathrm{H} 3$ = Market Orientation berpengaruh signifikan terhadap Kinerja Perusahaan

\section{HASIL DAN PEMBAHASAN}

Pada penelitian ini dilakukan uji kualitas data yaitu uji validitas dan reabilitas. Hasil uji masing masing adalah

\section{Tabel 2}

Uji vaiditas

\begin{tabular}{llcl}
\hline \multicolumn{1}{c}{ Variabel } & $\begin{array}{c}\text { Loading } \\
\text { Factor }\end{array}$ & Keterangan \\
\hline Cost & Pernyataan & 0,772 & Valid \\
Leadership & 1 & & \\
& Pernyataan & 0,831 & Valid \\
& 2 & & \\
& Pernyataan & 0,454 & Valid \\
& 3 & & \\
& Pernyataan & 0,850 & Valid \\
& 4 & & \\
& Pernyataan & 0,600 & Valid \\
& 5 & & \\
Differentation & Pernyataan & 0,890 & Valid \\
Strategy & 1 & & \\
\hline
\end{tabular}

Metode Analisa menggunkan Regresi berganda dengan batuan SPSS 21 .

Sebelum melakukan uji Regresi berganda dilakukan terlebih dahulu uji validitas dan reabilitas.

\begin{tabular}{|c|c|c|c|}
\hline & $\begin{array}{l}\text { Pernyataan } \\
2\end{array}$ & 0,927 & Valid \\
\hline & $\begin{array}{l}\text { Pernyataan } \\
3\end{array}$ & 0,663 & Valid \\
\hline & $\begin{array}{l}\text { Pernyataan } \\
4\end{array}$ & 0,860 & Valid \\
\hline & $\begin{array}{l}\text { Pernyataan } \\
5\end{array}$ & 0,921 & Valid \\
\hline & $\begin{array}{l}\text { Pernyataan } \\
6\end{array}$ & 0,921 & Valid \\
\hline \multirow{11}{*}{$\begin{array}{l}\text { Market } \\
\text { Orientation }\end{array}$} & Pernyataan & 0,894 & Valid \\
\hline & 1 & & \\
\hline & $\begin{array}{l}\text { Pernyataan } \\
2\end{array}$ & 0,927 & Valid \\
\hline & $\begin{array}{l}\text { Pernyataan } \\
3\end{array}$ & 0,886 & Valid \\
\hline & $\begin{array}{l}\text { Pernyataan } \\
4\end{array}$ & 0,889 & Valid \\
\hline & $\begin{array}{l}\text { Pernyataan } \\
5\end{array}$ & 0,614 & Valid \\
\hline & $\begin{array}{l}\text { Pernyataan } \\
6\end{array}$ & 0,850 & Valid \\
\hline & $\begin{array}{l}\text { Pernyataan } \\
7\end{array}$ & 0,491 & Valid \\
\hline & $\begin{array}{l}\text { Pernyataan } \\
8\end{array}$ & 0,890 & Valid \\
\hline & $\begin{array}{l}\text { Pernyataan } \\
9\end{array}$ & 0,927 & Valid \\
\hline & $\begin{array}{l}\text { Pernyataan } \\
10\end{array}$ & 0,763 & Valid \\
\hline \multirow{6}{*}{$\begin{array}{l}\text { Kinerja } \\
\text { Perusahaan }\end{array}$} & Pernyataan & 0,860 & Valid \\
\hline & 1 & & \\
\hline & $\begin{array}{l}\text { Pernyataan } \\
2\end{array}$ & 0,921 & Valid \\
\hline & $\begin{array}{l}\text { Pernyataan } \\
3\end{array}$ & 0,780 & Valid \\
\hline & $\begin{array}{l}\text { Pernyataan } \\
4\end{array}$ & 0,862 & Valid \\
\hline & $\begin{array}{l}\text { Pernyataan } \\
5\end{array}$ & 0,877 & Valid \\
\hline
\end{tabular}

Sumber : Data primer (2018)

Tabel 2

Uji Reliabilitas

\begin{tabular}{ccc}
\hline Variabel & $\begin{array}{c}\text { Cronbach's } \\
\text { Alpha }\end{array}$ & Kesimpulan \\
\hline $\begin{array}{c}\text { Cost Leadership } \\
\text { Differentation } \\
\text { Strategy }\end{array}$ & 0,815 & Reliabel \\
Market & 0,894 & Reliabel \\
Orientation & 0,820 & Reliabel \\
Kinerja & 0,921 & Reliabel \\
Perusahaan & & \\
\hline
\end{tabular}

Sumber : Data primer (2018) 


\section{Hasil Uji Hipotesis \\ Hasil Uji F}

Hasil uji $F$ memperlihatkan signifikansi 0,000 yang artinyavariabel cost leadership, Differentation Strategy, Market Orientation berpengaruh secara simultane terhadap Kinerja perusahaan.

Tabel 3

Uji F Cost leadership, Differentation

Strategy, Market Orientation terhadap

Kinerja Perusahaan

\begin{tabular}{ccc}
\hline $\begin{array}{c}\text { Variabel } \\
\text { Dependen }\end{array}$ & Signifikansi & Kesimpulan \\
\hline $\begin{array}{c}\text { Kinerja } \\
\text { Perusahaan }\end{array}$ & 0,000 & Signifikan \\
\hline
\end{tabular}

Sumber : Data primer (2018)

Hasil Uji t

Tabel 4

Uji F Cost leadership, Differentation

Strategy, Market Orientation terhadap

Kinerja Perusahaan

\begin{tabular}{|c|c|c|c|c|}
\hline Model & $\begin{array}{c}\text { Unstandardize } \\
\text { d Coefficients } \\
B\end{array}$ & Sig. & Kesimpulan & Hipotesis \\
\hline$($ Constant $)$ & 3,628 & 0,000 & & \\
\hline Cost leadership & 0,129 & 0,033 & Signifikan Positif & $\mathrm{H} 1$ \\
\hline $\begin{array}{l}\text { Differentation } \\
\text { Strategy }\end{array}$ & 0,166 & 0,023 & Tidak Signifikan & $\mathrm{H} 2$ \\
\hline $\begin{array}{l}\text { Market } \\
\text { Orientation }\end{array}$ & 1,1173 & 0,000 & Signifikan Positif & $\mathrm{H} 3$ \\
\hline
\end{tabular}

Sumber : Data primer (2018

Dari hasil uji t dapat disimpulkan bahwa $\mathrm{H} 1$ = cost leadership berpengaruh signifikan terhadap kinerja perusahaaan , di terima karena nilai signifikan lebih kecil 0,05 , ini sejalan dengan penelitian (Acquaah, 2011; Atikiya et al., 2015; Birjandi et al., 2014; Gonzalez-Benito \& Suarez-Gonzalez, 2010; Hassan et al., 2018; Hilman \& Kaliappen, 2014a; Hunjra et al., 2017; Kharub et al., 2018; Lo, 2012; Valipour et al., 2012). Cost leadership adalah salah satu strategi generik Porter yang dikejar perusahaan tidak secara langsung maupun langsung memengaruhi kinerja perusahaan, dengan memiliki biaya terendah dalam industri dan memungkinkan perusahaan untuk tetap kompetitif. Saat ini lingkungan kompetitif dan ekonomi terus berubah, yang sepenuhnya mengalihkan perhatian perusahaan dan memaksanya untuk berusaha keras bagaimana mempertahankan sumber daya fisik dan tidak berwujud untuk meningkatkan kinerja mereka dan membangun keunggulan kompetitif .Cost leadrrship adalah alat organisasi utama yang digunakan dalam meningkatkan kinerja industri dan mempromosikan keunggulan kompetitif. Oleh karena itu, strategi kepemimpinan biaya merupakan faktor yang berpengaruh yang dapat mengarah pada kinerja perusahaan yang aktif. Demikian pula, orientasi pasar telah diidentifikasi sebagai katalis untuk meningkatkan kinerja bisnis yang efektif dengan mempertimbangkan kebutuhan pelanggan sebagai filosofi organisasi teratas.

$\mathrm{H} 2=$ Differentation Strategy berpengaruh signifikan terhadap kinerja perusahaan, ini sejalan dengan (Al-siwidi \& Al-Hosam, 2012; Birjandi et al., 2014; Espino-rodríguez \& Chun, 2014; Hilman, Hai Kaliappen, 2014; Hilman \& Mohamed, 2011; Hingley et al., 2008; Lo, 2012; Nandakumar et al., 2011; Pehrsson, 2016; Teeratansirikool et al., 2013) Temuan dari penelitian ini menetapkan bahwa, tujuan penelitian pertama adalah untuk menguji pengaruh strategi diferensiasi pada kinerja Toko Oleh - Oleh menunjukkan bahwa strategi diferensiasi mempunyai efek pada kinerja Toko Oleh Oleh didukung. Oleh karena itu, kebutuhan akan regulator Toko Oleh - Oleh lebih berupaya dalam strategi pengurangan biaya dan juga menekankan pada peluang kemitraan dengan pandangan untuk mendapatkan keunggulan kompetitif. Jika perusahaan ingin menerapkan strategi 
diferensiasi, itu harus ditekankan desain inovatif dan sistem yang fleksibel untuk menghasilkan diferensiasi dalam produk atau proses pembuatan produk yang ada. Hasil studi mengkonfirmasi asumsi tersebut. Misalnya, Penekanan pada desain dan pengembangan proses memungkinkan perusahaan untuk menyesuaikan parameter proses dengan cepat, sehingga mengurangi kebutuhan kapasitas berlebih dan dengan demikian pengurangan biaya penggantian yang dapat diterjemahkan ke pengurangan harga dan pencapaian sistem yang

$\mathrm{H} 3=$ Market Orientation berpengaruh signifikan terhadap Kinerja Perusahaan, ini sejalan dengan (Al-Ansaari et al., 2015; Barnabas \& Mekoth, 2010; Brik et al., 2011; Charles et al., 2012; Dave, 2011; Fawzy et al., 2017; Ghanavati, 2014; Gruber-Muecke \& Hofer, 2015; Hassan et al., 2018; Kocak et al., 2017; Mokhtar, 2009; Obeidat, 2016; Obeidat et al., 2016; Oluwatoyin et al., 2018; Shehu \& Mahmood, 2014; Wilson et al., 2014). Untuk meningkatkan tingkat orientasi pasar, organisasi harus mengenali kebutuhan pelanggannya lebih baik daripada pesaing. Jika organisasi dapat mengenali lebih cepat layanan mana yang dibutuhkan pelanggan dan kemudian dapat memenuhi kebutuhan itu, tentunya ia akan mendapatkan lebih banyak pangsa pasar dan keuntungan. Jika organisasi tidak mengetahui aktivitas pesaing, itu tidak akan berkembang dalam perubahan pasar yang meningkat; karenanya direkomendasikan bahwa, untuk meningkatkan aspek orientasi pesaing, organisasi harus secara efisien dan akurat

Tabel 5

HUji Koefisien Determinasi

\begin{tabular}{cccc}
\hline Model & $\mathbf{R}$ & $\begin{array}{c}\mathbf{R} \\
\text { Square }\end{array}$ & $\begin{array}{c}\text { Adjusted } \\
\mathbf{R} \text { Square }\end{array}$ \\
\hline 1 & $0,770^{\mathrm{a}}$ & 0,593 & 0,588 \\
\hline
\end{tabular}

Sumber : Data primer (2018) fleksibel. Hasil penelitian ini menunjukkan bahwa dampak dari strategi diferensiasi lebih besar di hadapan kualitas. Desain dan pengembangan tampaknya memiliki asosiasi maksimum dengan kinerja yang diikuti oleh informasi dan analisis. Hasil studi mencatat bahwa informan yang memadai dan analisis yang tepat memiliki dampak signifikan pada kualitas produk sedangkan desain dan pengembangan yang efisien meningkatkan kualitas produk dan peningkatan proses.

mempertimbangkan pesaing dan memeriksa tindakan mereka. Organisasi harus mengumpulkan kebijakan keseluruhan untuk melakukan koordinasi antar fungsi dan penggunaan sumbersumber organisasi secara terkoordinasi. Bagian-bagian organisasi harus saling melengkapi tindakan masing-masing dengan mengakui Pro dan Kontra satu sama lain.

Hal ini ditekankan untuk membuat koordinasi antar fungsional dengan partisipasi bagian dalam mengumpulkan program dan strategi, distribusi sumber yang seimbang ke bagian yang berbeda dan kesadaran setiap bagian tentang bagaimana menyajikan penilaian yang lebih baik bagi pelanggan.

\section{Hasil Uji Koefisien Determinasi}

Dari tabel 5 menunjukan bahwa variabel independent yaitu cost leadership, Differentation Strategy, market orientation mampu menerangkan kinerja organisasi sebesar 59,3 persen, sisanya di pengaruhi oleh faktor lain di luar model.

\section{KESIMPULAN}

Dari penelitian ini dapat di seimpulkan bahwa cost leadership, Differentation Strategy, Market Orientation berpengaruh terhadap Kinerja Perusahaan. Cost leadrrship adalah alat organisasi utama yang digunakan dalam meningkatkan kinerja industri dan 
mempromosikan keunggulan kompetitif. Oleh karena itu, strategi kepemimpinan biaya merupakan faktor yang berpengaruh yang dapat mengarah pada kinerja perusahaan yang aktif. Demikian pula, orientasi pasar telah diidentifikasi sebagai katalis untuk meningkatkan kinerja bisnis yang efektif dengan mempertimbangkan kebutuhan pelanggan sebagai filosofi organisasi teratas. Jika perusahaan ingin menerapkan strategi diferensiasi, itu harus ditekankan desain inovatif dan sistem yang fleksibel untuk menghasilkan diferensiasi dalam produk atau proses pembuatan produk yang ada.

Untuk meningkatkan tingkat orientasi pasar, organisasi harus mengenali kebutuhan pelanggannya lebih baik daripada pesaing. Jika organisasi dapat mengenali lebih cepat layanan mana yang dibutuhkan pelanggan dan kemudian dapat memenuhi kebutuhan itu, tentunya ia akan mendapatkan lebih banyak pangsa pasar dan keuntungan. Jika organisasi tidak mengetahui aktivitas pesaing, itu tidak akan berkembang dalam perubahan pasar yang meningkat; karenanya direkomendasikan bahwa, untuk meningkatkan aspek orientasi pesaing, organisasi harus secara efisien dan akurat mempertimbangkan pesaing dan memeriksa tindakan mereka.

Disarankan untuk menggunakan riset pemasaran untuk mengenali kebutuhan dan keinginan pelanggan, Pro dan Kontra pesaing dan untuk mengoptimalkan kegiatan pemasaran dan berlayar.

\section{DAFAR PUSTAKA}

Abu Aliqah, K. M. (2012). Differentiation and Organizational Performance: Empirical Evidence from Jordanian Companies. Journal of Economics, 3(1), 7-11.

Acquaah, M. (2011). Business strategy and competitive advantage in family businesses in Ghana: The role of social networking. Journal of Developmental Entrepreneurship,
16(01), 103-126.

Al-Ansaari, Y., Bederr, H., \& Chen, C. (2015). Strategic orientation and business performance: an empirical study in the UAE context. Management Decision, 53(10). https://doi.org/10.1108/00251741211 216232

Al-siwidi, A. K., \& Al-Hosam, A. (2012). The effect of entrepreneurial orientation on the organizational performance: A study on Islamic banks in Yemen using the Partial Least Squares approach. African Journal of Business Management, 2(1), 156-164.

Atikiya, R., Mukulu, E., \& Waiganjo, E. (2015). Effect of Cost Leadership Strategy on the Performance of Manufacturing Firms in Kenya. The Strategic Journal of Business and Change Management, 2(8), 134.143.

Azim, S., Abdullah, H. H., \& Gorondutse, A. H. (2017). Competitive Strategy and Firm Performance: A Review of Literature. International Journal of Business and Technopreneurship, 7(1), 87-92.

Barnabas, N., \& Mekoth, N. (2010). Autonomy, market orientation and performance in Indian retail banking. Asia Pacific Journal of Marketing and Logistics, 22(3), 330-350.

Birjandi, H., Jahromi, N. ., Darabi, S. ., \& Birjandi, M. (2014). The Effect of cost leadership strategy on ROA and future performance of accepted companies in tehran stock exchange. Research Journal of Finance and Accounting, 5(7), 152-158.

BPS. (2019). STATISTIK Perkembangan Pariwisata dan Transportasi Nasional.

Brik, A. Ben, Rettab, B., \& Mellahi, K. (2011). Market Orientation, Corporate Social Responsibility, and Business Performance. Journal of Business Ethics, 99(3), 307-324. https://doi.org/10.1007/s10551-0100658-z

Cavusgil, S. T., Ghauri, P. N., \& Akcal, A. 
A. (2013). Doing Business in Emerging Markets. SAGE, London., 2nd.

Charles, L., Joel, C., \& Samwel, K. C. (2012). Market Orientation and Firm Performance in the Manufacturing Sector in Kenya. European Journal of Business and Management, 4(10), 2222-2839.

Dave, A. S. and S. (2011). Entrepreneurial Orientation and Innovation Performance: The Mediating Role of Knowledge Management. SCMS Journal of Indian Management, 6(1), 257-275.

https://doi.org/10.1177/02662426124 55034

Ehie, I., \& Muogboh, O. (2016). Analysis of manufacturing strategy in developing countries: a sample survey of Nigerian manufacturers. Journal of Manufacturing Technology Management, 27(2), 234-260.

Espino-rodríguez, T. F., \& Chun, P. (2014). Activity outsourcing and competitive strategy in the hotel industry . The moderator role of asset specificity. International Journal of Hospitality Management, 42, 9-19. https://doi.org/10.1016/j.ijhm.2014.06 .005

Fawzy, H., Abuzid, T., \& Abbas, M. (2017). Banks Performance and Impact of Market Orientation Strategy: Do Employee Satisfaction and Customer Loyalty Augment this Relationship? International Review of Management and Marketing, 7(2), 60-66.

Ghanavati, M. (2014). The effect of corporate culture and market orientation on Iranian industrial SMEs' performance. Iranian Journal of Management Studies, 7(2), 413436.

Gonzalez-Benito, J., \& Suarez-Gonzalez, I. (2010). A study of the role played by manufacturing strategic objectives and capabilities in understanding the relationship between Porter's generic strategies. British Journal of Management, 21(4), 1027-1043.

Gorondutse, A. H., \& Hilman, H. (2017). Influence of differentiation strategy on performance of hotels: the moderating role of environmental munificence. Www.Jbrmr.Com A Journal of the Academy of Business and Retail Management, 11(4), 150161.

https://doi.org/10.24052/JBRMR/V11 IS04/IODSOPOHTMROEM

Gruber-Muecke, T., \& Hofer, K. M. (2015). Market orientation, entrepreneurial orientation and performance in emerging markets. International Journal of Emerging Markets, 10(3), 560-571. https://doi.org/10.1108/IJoEM-052013-0076

Hassan, A., Dutse, G., Aliyu, M. S., Utara, U., Academy, N. P., Kano, W., ... Orientation, M. (2018). Cost Leadership , Market Orientation and Business Performance: An Empirical Investigation. Journal of Quantitative Methods, 2(2).

Hilman, Hai Kaliappen, N. (2014). Strategic Role of Customer Orientation in Differentiation Strategy and Organizational Performance Nexus: A Partial Least Square ( PLS ). Research Journal of Applied Sciences, Engineering and Technology, 7(19), 4150-4156. https://doi.org/10.19026/rjaset.7.780

Hilman, H., \& Kaliappen, N. (2014a). Do cost leadership strategy and process innovation influence the performance of Malaysia hotel industry? Asian Social Science, 10(10), 134-141. https://doi.org/10.5539/ass.v10n10p1 34

Hilman, H., \& Kaliappen, N. (2014b). Market Orientation Practices and Effects on Organizational Performance : Empirical Insight From Malaysian Hotel Industry. SAGE Open.

https://doi.org/10.1177/21582440145 
53590

Hilman, H., \& Mohamed, Z. A. (2011). Sourcing strategies, practices and effects on organisational performance. J. for Global Business Advancement, $\quad 4(1), \quad 18$. https://doi.org/10.1504/jgba.2011.040 332

Hingley, M., Sodano, V., \& Lindgreen, A. (2008). Differentiation strategies in vertical channels A case study from the market for fresh produce. British Food Journal, 110(1), 42-61.

Hunjra, A. I., Faisal, F., \& Gulshion, F. (2017). The Impact of Cost Leadership Strategy and Financial Management Control Systems on Organizational Performance in Pakistan's Services Sector. The Lahore Journal of Business, 6(1), 119.

Kementerian Pariwisata Indonesia. (2017). Laporan Akuntabilitas Kinerja Kementerian Pariwisata Tahun 2017. Kementerian Pariwisata, 134. Retrieved from http://www.kemenpar.go.id/asp/detil. asp? $=16 \& i d=3101$

Kharub, M., Mor, R. S., \& Sharma, R. (2018). The relationship between cost leadership competitive strategy and firm performance: A mediating role of quality management. Journal of Manufacturing Technology Management.

https://doi.org/10.1108/JMTM-062017-0116

Kharub, M., Patle, B. K., \& Sharma, G. (2016). The Relationship between Differentiation Strategy and Firm Performance: a Mediating Role of Quality Management. IOSR Journal of Mechanical and Civil Engineering (IOSR-JMCE), (2278-1684,p-ISSN: 2320-334X), 66-71.

Kocak, A., Carsrud, A., \& Oflazoglu, S. (2017). Market, entrepreneurial, and technology orientations: impact on innovation and firm performance. Management Decision, 55(2).
Lo, Y.-H. (2012). Back to Hotel Strategic Management 101: An Examination of hotels ' Implementation of Porter' s Generic Strategy in China. The Journal of International Management Studies, $\quad 7(1), \quad 56-70$. https://doi.org/10.3406/caief.1962.22 26

Mata, B. A. ., \& Aliyu, M. . (2014). The Relationship Between Some Determinants Of SME Performance In Nigeria: A Qualitative Approach. European Journal of Business and Management, 6(2), 107-114.

Mokhtar, S. (2009). Market orientation critical success factors of Malaysian manufacturers and its impact on financial performance. International Journal of Marketing Studies, 1(1), 77-84.

Nandakumar, M., K., Ghobadian, A., \& Regan, N. O. (2011). Business-level strategy and performance: The moderating affect of environment and structure. Management Decision, 48(6), 907-939.

Obeidat, B. Y. (2016). The Effect of Strategic Orientation on Organizational Performance: The Mediating Role of Innovation. International Journal of Communications, Network and System Sciences, 09(11), 478-505. https://doi.org/10.4236/ijens.2016.91 1039

Obeidat, B. Y., Al-Suradi, M. M., Masa'deh, R., \& Tarhini, A. (2016). The impact of knowledge management on innovation An empirical study on Jordanian consultancy firm. Management Research Review, 39(10), 1214-1238. https://doi.org/10.1108/JHOM-092016-0165

Oluwatoyin, A. M., Olufunke, A. P., \& Salome, I. O. (2018). The Impact of Market Orientation on Performance of Selected Hotels in Ondo State, Nigeria. Journal of Business and Management, $\quad 6, \quad 616-631$. 
https://doi.org/10.4236/ojbm.2018.63 047

Pehrsson, A. (2016). How does a foreign subsidiary's differentiation strategy fit competitive dynamics and mandate? European Business Review, 28(6), 690-708.

Shehu, A. M., \& Mahmood, R. (2014). An empirical analysis of market orientation and business performance relationship in the context of developing economy. International Journal of Academic Research in Business and Social Sciences, 4(9), 457-470.

Teeratansirikool, L., Siengthai, S., Badir, Y., \& Charoenngam, C. (2013). Competitive strategies and firm performance: the mediating role of performance measurement. International Journal of Productivity and Performance Management, 62(2), 168-184.

Valipour, H., Birjandi, H., \& Honarbakhsh, S. (2012). The effects of cost leadership strategy and product differentiation strategy on the performance of firms. Journal of Asian Business Strategy, 2(1), 14-23.

Waddel, D., \& Stewart, D. (2008). Knowledge management as perceived by quality practitioners. The TQM journal, 20(1), 31-44. The TQM Journal, 20(1), 31-44.

Wilson, G. A., Perepelkin, J., Zhang, D. Di, \& Vachon, M.-A. (2014). Market Orientation, Alliance Orientation, and Business Performance in the Biotechnology Industry. Journal of Commercial Biotechnology, 20(2). https://doi.org/10.5912/jcb645

World Travel and Tourism Council, \& Oxford Economics. (2018). Travel \& Tourism Power and Performance September 2018. Retrieved from https://www.wttc.org//media/files/reports/2018/power-andperformance-rankings-2018.pdf

Yuliansah, Y., Rammal, H. G., \& Rose, E. (2016). Business strategy and performance in Indonesia's service sector. Journal of Asia Business Studies, 10(2), 164-182. 